\title{
CORRECTION
}

View Article Online

View Journal I View Issue

\section{Correction: Partially embedded gold nanoislands in a glass substrate for SERS applications}

Cite this: RSC Adv., 2015, 5, 1949

\author{
Mohammad Tariq Yaseen, ${ }^{\text {abc }}$ Minfeng $C h e n^{c}$ and Yia-Chung Chang ${ }^{* c d}$ \\ Correction for 'Partially embedded gold nanoislands in a glass substrate for SERS applications' by \\ Mohammad Tariq Yaseen et al., RSC Adv., 2014, 4, 55247-55251.
}

DOI: $10.1039 / c 4 r a 90052 a$

www.rsc.org/advances

The affiliations were not displayed correctly in the original manuscript. The correct affiliations are as follows:

${ }^{\mathrm{a}}$ Department of Engineering and System Science, National Tsing Hua University, Hsinchu 300, Taiwan.

${ }^{\mathrm{b}}$ Nano Science and Technology Program, Taiwan International Graduate Program, Academia Sinica and National Tsing Hua University, Taipei 115 , Taiwan.

${ }^{c}$ Research Centre for Applied Sciences, Academia Sinica, Taipei, 115, Taiwan.

${ }^{\mathrm{d}}$ Department of Physics, National Cheng Kung University, Tainan, 701, Taiwan, Email: yiachang@gate.sinica.edu.tw.

The Royal Society of Chemistry apologises for these errors and any consequent inconvenience to authors and readers. 